\title{
The Turkish Version of the Grandiose Narcissism Scale: A Validity and Reliability Study of Football Team Fans
}

\author{
By Caner Özgen * \\ Metin Argan ${ }^{\prime}$
}

\begin{abstract}
Literature about narcissism has been the subject of studies in many different disciplines including sports sciences. The studies about narcissism in sport generally are for determining the level of athletes' narcissism, but there are no studies which examines the level of football team fans narcissism. In light of the foregoing, there are two purpose of this study: 1) To examine the factor structure of GNS (Grandiose Narcissism Scale) in Turkish culture. 2) To reveal relationship between demographic variables and narcissism levels of sport fans. The study involved a quantitative research methodology and convenience sampling with a total sample of 275 sports fan. The data were subjected to, an exploratory factor analysis (EFA), confirmatory factor analysis (CFA), t-test, analysis of variance (ANOVA) and correlation analysis. After conducting the analyzes seven aspects of GNS revealed as in the original scale, which are authority, self-sufficiency, superiority, vanity, exhibitionism, entitlement and exploitativeness. According to results of ANOVA and t-tests, it is found out that there were significant differences between some demographic variables of football fans and authority, vanity dimension.
\end{abstract}

Keywords: Narcissism, Football Fans, Validity, Reliability

\section{Introduction}

The concept of narcissism, rooted in the British scientist Ellis's clinical research on individuals' perverse self-love, is named after the Greek myth of Narcissus in which he falls in love with his reflection on the waters of a lake and gets drowned while trying to hug this reflection (Lothane, 1995). Narcissistic individuals are characterized by having a high self-esteem (Gabriel, et al., 1994), being arrogant and selfish (Campbell, et al., 2004), and perceiving themselves as much more special and superior than others (Morf and Rhodewalt, 2001). Such extreme self-attention and self-interest bordering on pathological narcissism is considered as a personality disorder (Kernberg, 1985). The body of research carried out after the 1980s (Emmons, 1984; Raskin and Terry, 1988) has established that narcissism is not only a pathological problem, but also, as mentioned by Freud (1914), everybody has it to some extent as part of their personality. The American Psychiatric Association (APA), (2000) defined this type of narcissism as Grandiose Narcissism in DSM IV (Diagnostic and Statistical Manual of Mental Disorders).

\footnotetext{
* Senior Lecturer, Research Assistant, Anadolu University, Faculty of Sport Sciences, Sports Management Department, Turkey.

$\dagger$ Lecturer, Professor Doctor, Head of the Department of Sports Management, Anadolu University, Faculty of Sport Sciences, Sports Management Department, Turkey.
} 
In order for narcissistic levels of people to be measured accurately and precisely, the conceptual framework in this context requires its seven dimensions to be considered (APA, 2000; Krenberg 1985; Raskin and Terry, 1988). These structures include Authority (to choose to take responsibility), Self-sufficiency (to choose to do their own work themselves), Vanity (giving importance to physical appearance too much), Superiority (thinking superior to others), Exhibitionism (acting in a way that attracts attention to others) Entitlement (to think that it deserves special attention), Exploitativeness (to provide benefit by using others).

Narcissistic Personality Inventory (NPI) developed by Raskin and Terry (1988) has been used by numerous studies in social sciences to investigate the concept of narcissism. NPI, which is one of the limited measuring instruments in the literature which shows the seven dimensions that express the theoretical sub-structure of narcissism at the level of sufficient validity and reliability, has been used in many subsequent studies but has failed to reach the sufficient validity and reliability level (Corry et al., 2008; del Rosario and White, 2005; Foster and Campbell, 2003). Foster et al., (2015) suggested that the solution of this problem lies in the creation of completely new items. Thus, they developed a scale that reveals the seven dimensions that are all composed of new items and reached a high level of validity and reliability.

There are many studies on narcissism in the sports science literature (Davis and Scott-Robertson, 2000; Elman and McKelvie, 2003; Miller and Mesagno, 2014). Most of these studies aimed at determining the level of narcissism of athletes and so far only a limited number of studies have examined the narcissistic levels of sports fans. In the light of the cited literature, the present study has two main purposes. The first objective of the study is to determine the suitability of the factor structure to Turkish football fans by conducting validity and reliability studies of Foster et al., (2015) Grandiose Narcissism Scale (GNS). The second objective of the study is to reveal the relationship between the level of narcissism and demographic variables of sports fans, their match participation behaviors, and the teams they favor. The fact that the study is one of the few studies in the literature focusing on the relation of narcissism and sports fandom and the fact that it is one of the few studies that comprise the seven dimensions expressed in the international literature by the conceptual framework of narcissism underscores the originality and importance of this study.

\section{Literature Review}

\section{Narcissism}

Vaknin, (2001) defines narcissism as behavioral patterns that are obsessive, selfish, egoistic and ambitious and constantly seeking satisfaction. Such narcissist patterns cause the individual to care about himself/herself much more than he or she needs, and to completely ignore others, thus causing problems in social relations. However, such patterns may not always lead to negative consequences; 
it has been expressed by many researchers that the positive self-perception of the individual is actually regarded as a healthy narcissism, and that it can contribute to the progress of the individual towards accomplishing his/her goals (Lubit 2002; Robertsa, et al., 2013).

\section{Sports and Narcissism}

The concept of narcissism has been the subject of many different researches in the sport science literature. Robertsa, et al., (2013) found that the high narcissistic levels of athletes positively and significantly affected their psychological performances. Miller and Mesagno, (2014) and Spano, (2001) found a significant relationship between exercise dependence and narcissism. Wallace and Baumeister, (2002) indicated that individuals with high levels of narcissism were less stressed than those with low narcissistic levels during any competition. Elman and McKelvie, (2003) argued that narcissistic individuals are physically more successful in extreme sports because their narcissistic emotions are advantageous to them. Geukes, et al., (2012) showed that the performances of narcissistic individuals were higher than those of nonnarcissistic individuals in high-stress sports competitions. Davis, (1992) stated that narcissistic individuals are extreme exercise addicts, because they increase their self-esteem by exercising. Brown and Graham, (2008) found that narcissism influenced sexual preferences and body satisfaction in a study of gay men and normal men actively engaged in bodybuilding.

\section{Sports Fandom and Narcissism}

Funk and James, (2001) define team identification as an individual's psychological contact with other team members and with the team. It has been revealed in different studies in sport science literature that feeling emotional attachment to a group is one of the most important factors in psychological well-being and developing personal self-sufficiency (Branscombe and Wann, 1991; Koo, et al., 2015). As the theoretical sub-structure of the narcissism literature, "personal self-sufficiency" has been discussed in many studies as an important dimension of narcissism (Foster, et al., 2015; Raskin and Terry, 1988). Murrell and Dietz, (1992) stated that thinking that they reflect their identities, sports fans felt a high level of commitment to their teams and to their fan clubs. Therefore, Linstead, (1997) reported that narcissistic individuals are highly committed to groups. In relation to this, Schwartz, (1987) stated that narcissistic individuals would feel a high degree of commitment if their organizational goals overlap with their own goals. Helping them satisfy their narcissistic feelings, narcissistic individuals believe that the world revolves around their own fan clubs, and therefore around them. 
Vol. 4, No. 3 Özgen et al.: The Turkish Version of the Grandiose Narcissism Scale...

\section{Methodology}

\section{Data Collection Instruments}

GNS was used in order to measure narcissism levels of the fans. The GNS is consisted of 35 items each responded by Likert-type scale $(1=$ strongly disagree, $5=$ strongly agree). The scale had 35 items and 7 factors.

\section{Sampling and Data Collection}

The sampling of this study consist of Besiktas, Fenerbahce, Galatasaray (accepted as "Tree Bigs" of Turkish Super League) fans. Convenience sampling method was used to collect data from fans. In this manner, data was collected via electronic forms and traditional way. In order to collect data online announcements were made on social networking sites and the participants were informed clearly according to the purpose of the study. To avoid a participant to fill out more than one questionnaire, IP's were limited. Most of the respondents (201) were reached along with online method. The rest were reached by the traditional way and the purpose of the study was explained individually. The participants who declared that they do not support the "three bigs" weren't considered in the study. Questionnaires were answered while the presence of the researchers. Each of the questionnaires took around 15 minutes to answer. A total of 102 questionnaires were distributed, 74 of which were completely answered resulting in a total return rate of $83.3 \%$. In total 275 fans were reached (201 via online and 74 traditional way).

\section{Findings/Results}

\section{Participants}

The participants are composed of $77,8 \%$ men and $22,2 \%$ women. A majority of all participants are 18 to 35 age range $(51,3 \%), 10,9 \%$ are 36 years old and above, $37,8 \%$ are between 26 and 35 years old. Considering the education status of the participants $12,7 \%$ are primary school and high school graduate, $66,2 \%$ are undergraduate and $21,1 \%$ are post graduate. A majority of all participants haven't watched any of their team's matches in a stadium $(42,2 \%)$ of the while $34,9 \%$ participants watched at least 3 or less matches and $22,9 \%$ watched 4 or more matches in a stadium. With regard to the away watch behavior of respondent, $72 \%$ of the participants hasn't watched any of the away matches of their teams in a stadium while $21,8 \%$ watched at least 3 or less and the rest $6,2 \%$ have watched 4 or more matches. In addition these information, percentage of the fans according to their teams are $41,4 \%$ Galatasaray, 31,3\% Fenerbahce and 27,3\% Besiktas. 


\section{Explanatory Factor Analysis (EFA)}

Table 1. Pattern Matrix Resulting from EFA, Cronbach's Alpha Results of the 35 GNS Items

\begin{tabular}{|c|c|c|c|}
\hline Factors & $\begin{array}{c}\text { Factor } \\
\text { loading } \\
(\boldsymbol{\beta})\end{array}$ & Mean & $S D$ \\
\hline Factor 1: Authority (4 items) & & & \\
\hline I like to be in charge of things. & 767 & 4,08 & ,84 \\
\hline I lead rather than follow. & 607 & 4,06 & ,92 \\
\hline I naturally take charge in situations. & 670 & 4,04 & ,91 \\
\hline I have a take charge personality. & ,658 & 4,18 & ,90 \\
\hline Factor 2: Self-Sufficiency (5 items) & & & \\
\hline I don't rely on other people to get things done. & ,635 & 4,12 & ,91 \\
\hline When something needs to be done, I do it on my own. & 697 & 4,22 & 83 \\
\hline I get irritated when I have to depend on other people. & 693 & 4,33 & ,94 \\
\hline I don't like to depend on other people to do things. &, 727 & 4,25 & ,95 \\
\hline I like to do things on my own. & ,613 & 4,40 &, 83 \\
\hline Factor 3: Superiority (5 items) & & & \\
\hline I'm more talented than most other people. & ,734 & 3,46 & ,97 \\
\hline I'm better than other people at most things. &, 769 & 3,47 & 91 \\
\hline If it's just me versus another person, I almost always win. & ,755 & 3,14 & ,88 \\
\hline I'm a superior person. & 685 & 2,92 & 1,02 \\
\hline I have more going for me than most people. & 497 & 3,26 &, 98 \\
\hline Factor 4: Vanity (5 items) & & & \\
\hline I care about how good I look. & ,800 & 3,86 & ,98 \\
\hline I try to look as attractive as possible when I leave the house. & 710 & 3,65 & 1,03 \\
\hline Looking good is important to feeling good. & 817 & 4,09 & ,99 \\
\hline My looks are important to me. & 836 & 3,87 & 1,07 \\
\hline I think it's important to look as good as possible. & 812 & 3,92 & 1,03 \\
\hline Factor 5: Exhibitionism (7 items) & & & \\
\hline I do things that grab people's attention. & ,806 & 2,73 & 1,15 \\
\hline I do things that get people to notice me. & ,884 & 2,62 & 1,15 \\
\hline I make myself the center of attention. &, 796 & 2,40 & 1,12 \\
\hline I can be a showoff. &, 594 & 2,96 & 1,11 \\
\hline I do things to get attention. & 861 & 2,51 & 1,12 \\
\hline I expect to be treated better than average. & .763 & 2,65 & 1,17 \\
\hline $\begin{array}{l}\text { The level of treatment I expect is higher than what most other people } \\
\text { expect }\end{array}$ & ,753 & 2,59 & 1,16 \\
\hline Factor 6: Entitlement (3 items) & & & \\
\hline I deserve to get what I want. & ,537 & 3,57 & 1,13 \\
\hline I expect people to bend the rules for me. & 604 & 2,74 & 1,06 \\
\hline I deserve more out of life than other people. & 639 & 2,88 & 1,10 \\
\hline Factor 7: Exploitativeness (5 items) & & & \\
\hline $\begin{array}{l}\text { I'll do whatever it takes to get ahead, even if it means some } \\
\text { people get hurt. }\end{array}$ & ,704 & 1,81 & 1,10 \\
\hline $\begin{array}{l}\text { If I have to take advantage of somebody to get what I want, so be } \\
\text { it. }\end{array}$ & 684 & 2,12 & 1,13 \\
\hline I can be pretty manipulative. & ,773 & 1,84 & 1,10 \\
\hline I'm willing to manipulate others to get what I want. & 887 & 1,65 & 1,01 \\
\hline I've been known to use people to get what I want. & ,710 & 1,38 &, 83 \\
\hline
\end{tabular}

Cronbach's Alpha ( $\boldsymbol{\alpha}$ ) value respectively;, $826 ;, 842 ;, 852 ;, 930 ;, 933 ;, 776 ;, 885$.

Eigenvalue (The percentage of variance) respectively; $8,46(24,184) ; 5,34$ (15,27); 2,69 $(7,69) ; 1,89(5,40) ; 1,46(4,17) ; 1,17(2,99) ; 1,049(2,99)$. 
In order to be able to apply the explanatory factor analysis (EFA) to the instrument used to determine the narcissistic levels of the participants, the sample adequacy measure needs to be determined (Zhang et al., 2003). For this purpose, Kaiser-Meyer Olkin (KMO) test was performed on the data obtained and the value 0.87 was found. According to Kaiser (1974), this value is within the range that indicates that the level of the sample is sufficient for the factor analysis. However, utilized to determine whether the data come from a multivariate normal distribution and whether there is a significant relationship between the data, the Bartlett Test for Sphericity (BTS), 6412,461 ( $\mathrm{p}<0.00)$ test was found as significant. The data obtained from the fans according to these results are shown to be suitable for performing explanatory factor analysis.

The principal components factor analysis and Promax rotation were used in order to group, classify and transform the 35 items included in the measurement tool used to determine the narcissistic levels of the fans. The results obtained from the analyses are shown in Table 1.

As Kaiser (1974) points out, those above an eigenvalue of 1 are included in the factor structure. In addition, items with a factor load of less than 0.41 were excluded from the measurement for confirmatory factor analysis. Accordingly, the items are grouped under seven factors as in the original measurement. The "born leader" item on the original scale in the dimension of 'authority' was removed from the measuring instrument because it could not reach the sufficient factor load.

\section{Correlation between Factors}

When the correlation matrix between the seven factors revealed in narcissism scale is examined, it is seen that there is no significant relationship between the "self-sufficiency" dimension and the "exhibitionism" dimension, and between the "vanity" dimension and the "exploitativeness" dimension, and all the remaining dimensions are related to each other at various levels (Table 2). "authority" and "self-sufficiency" dimensions $(\mathrm{r}=0.520)$ were found to be the most correlated dimensions among them.

Table 2. Correlation Matrix between the Factors

\begin{tabular}{|l|c|c|c|c|c|c|c|}
\hline & \multicolumn{1}{|c|}{1} & \multicolumn{1}{|c|}{2} & 3 & 4 & 5 & 6 & 7 \\
\hline Factor-1 Authority & 1.000 & & & & & & \\
\hline $\begin{array}{l}\text { Factor-2 } \\
\text { Selfsufficiency }\end{array}$ &, $520^{* *}$ & 1.000 & & & & & \\
\hline Factor-3 Superiority &, $210^{* *}$ &, $140^{*}$ & 1.000 & & & & \\
\hline Factor-4 Vanity &, $370^{* *}$ &, $270^{* *}$ &, $356^{* *}$ & 1.000 & & & \\
\hline $\begin{array}{l}\text { Factor-5 } \\
\text { Exhibitionism }\end{array}$ &, $125^{* *}$ &, 008 &, $339^{* *}$ &, $404^{* *}$ & 1.000 & & \\
\hline Factor-6 Entitlement &, $136^{*}$ &, $124^{*}$ &, $452^{* *}$ &, $269^{* *}$ &, $448^{* *}$ & 1.000 & \\
\hline $\begin{array}{l}\text { Factor-7 } \\
\text { Exploitativeness }\end{array}$ &,$- 159^{*}$ & - &, $273^{* *}$ &,- 005 &, $309^{* *}$ &, $398^{* *}$ & 1.000 \\
\hline Mean & 4,06 & 4,26 & 3,25 & 3,88 & 2,64 & 3,06 & 1,76 \\
\hline Standard deviation &, 72 &, 70 &, 74 &, 90 &, 96 &, 90 &, 86 \\
\hline
\end{tabular}

$* \mathrm{p}<0.05 * * \mathrm{p}<0.01$ 


\section{Reliability and Validity}

The total Cronbach's alpha value of each factor and of the measuring instrument was calculated in order to determine the internal consistency of the factors, as shown in Table-2. As the total Cronbach's Alpha value (0.90) was calculated, the dimensions of "authority" dimension was taken as 0.82 , "selfsufficiency" dimension as 0.84 , "superiority" dimension as 0.85 , "vanity" dimension as 0.93, "exhibitionism" as 0.93 , "entitlement" dimension as 0.76 , and "exploitativeness" dimension as 0.88 . According to this, the total scale and each dimension within the scale were found to be in the range of sufficient reliability level (Bagozzi and Yi, 1988). Bagozzi and Yi, (1988) states that a factor loading exceeding 0.70 as evidence of convergent validity. Child, (1990) defined a factor loading value of 0.50 and above is take account of good and very significant, whereas 0.45 is fair and 0.32 and below is poor. As it is shown in the Table-1, factor loadings demonstrate suitable item convergence on the intended constructs. Byrne, (2001) indicated that constructs that do not have high correlations provide discriminant validity. As shown in the Table 2, correlations between factors were not higher than 0.70 , in light of this information; we can consider this as an evidence for discriminant validity.

\section{Confirmatory Factor Analysis (CFA)}

Based on EFA results, 34 items of GNS were then subjected to a confirmatory factor analysis (CFA), using AMOS 20. Some modifications were proposed as a result of the CFA conducted. In the light of these propositions, a total of four modifications were made. All the modifications were made within the items located under the same dimension, and the theoretical structure of the scale was thus not damaged. These modifications are the 3th and 4th items in the "self-sufficiency" dimension, the 1th and 2th items in the "superiority" dimension, the 1-2 and 6-7 items in the "exhibitionism" dimension. The minimum chi-square value of the generated model was found to be significant $(\chi 2=912,739, \mathrm{p}=0.00)$, and resulted as $\chi^{2} / \mathrm{df}=1.81$. Thus, the fit index values of the examined model were $\mathrm{RMSEA}=0.055, \mathrm{CFI}=0.93$, $\mathrm{IFI}=0.93$, TLI $=92$, GFI $=0.84$. When these values are examined, they are found to be at the acceptable level as suggested by the relevant literature (Bentler, 1999; Bove and Johnson, 2006), although the GFI values are slightly below the desired level but still acceptable (Bagozzi and Yi, 1988). These results show that the factor structure obtained by EFA is confirmed by CFA, and that the factor structure of the GNS is a valid model. 
Vol. 4, No. 3 Özgen et al.: The Turkish Version of the Grandiose Narcissism Scale...

Figure 1. Pattern Matrix Resulting from EFA, Cronbah's Alpha Results of the 34 GNS Items

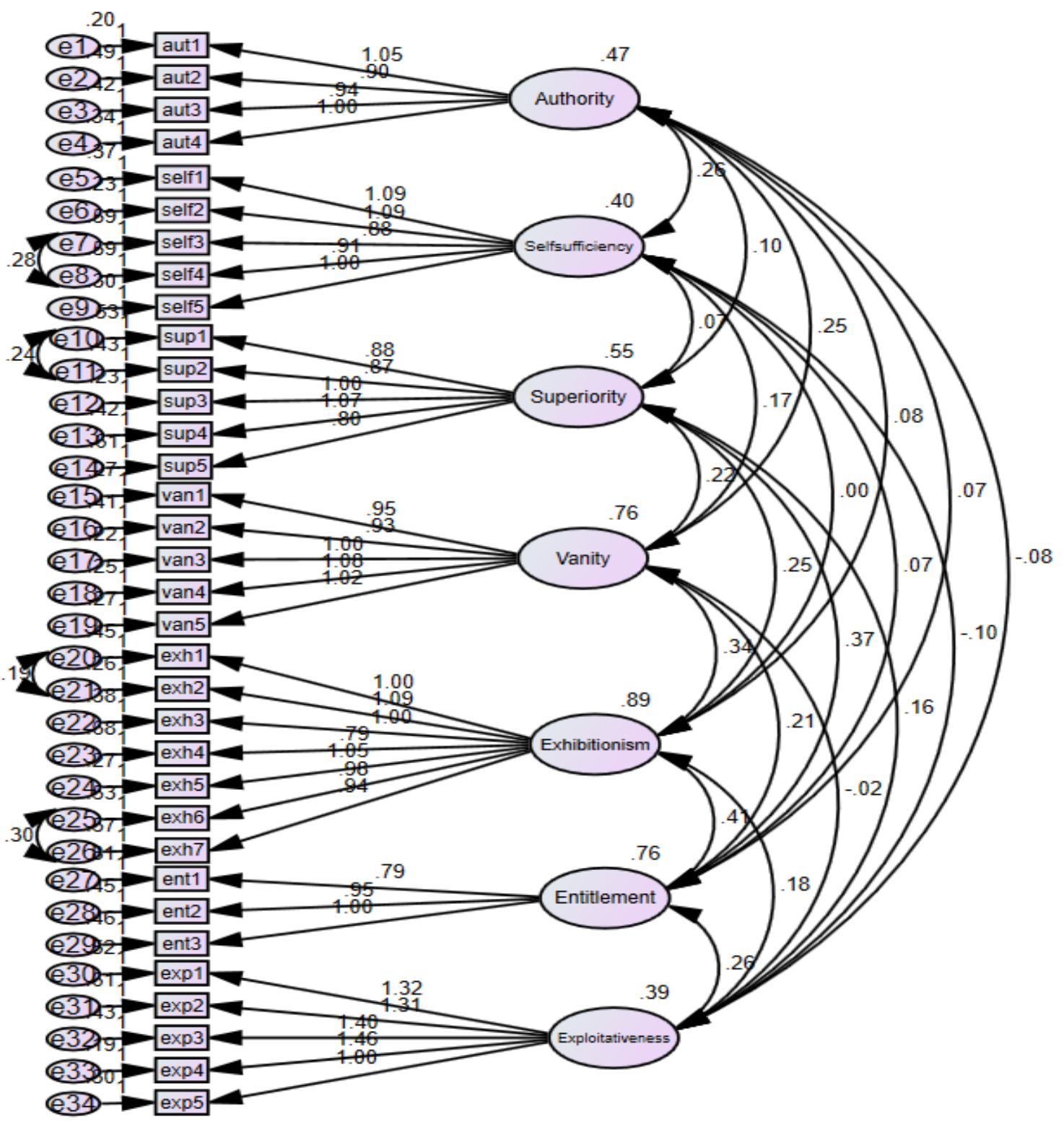

Fit indices: $\chi^{2}=912,739(\mathrm{P}=0.000), \chi^{2} / \mathrm{df}=1.81 . \mathrm{RMSEA}=0.055, \mathrm{CFI}=0.93, \mathrm{IFI}=0.93$, $\mathrm{TLI}=92, \mathrm{GFI}=0.84$

Findings on Sports Fans' Demographic Characteristics regarding the Narcissistic Scale Dimensions

Independent groups t-test was applied to determine the relationship between the GNS dimensions and the gender of sports fans. The analyses revealed that the dimension of "authority" differs significantly according to gender. 
Table 3. $t$-test Result according to Gender of Sports Fans

\begin{tabular}{|c|c|c|c|c|c|c|}
\hline Factor & Gender & $\mathbf{N}$ & Mean & SD. & $\mathbf{T}$ & $\mathbf{P}$ \\
\hline \multirow{2}{*}{ Authority } & Female & 81 & 3.95 & 0.73 & \multirow{2}{*}{$-2,06$} & \multirow[t]{2}{*}{$0.040^{*}$} \\
\hline & Male & 194 & 4.15 & 0.71 & & \\
\hline \multirow[t]{2}{*}{ Self-sufficiency } & Female & 81 & 4.23 & 0.73 & \multirow[t]{2}{*}{-0.50} & \multirow[t]{2}{*}{0.616} \\
\hline & Male & 194 & 4.28 & 0.69 & & \\
\hline \multirow[t]{2}{*}{ Superiority } & Female & 81 & 3.31 & 0.69 & \multirow[t]{2}{*}{0.85} & \multirow[t]{2}{*}{0.391} \\
\hline & Male & 194 & 3.22 & 0.78 & & \\
\hline \multirow{2}{*}{ Vanity } & Female & 81 & 3.99 & 0.89 & \multirow[t]{2}{*}{1.33} & \multirow[t]{2}{*}{0.183} \\
\hline & Male & 194 & 3.83 & 0.90 & & \\
\hline \multirow[t]{2}{*}{ Exhibitionism } & Female & 81 & 2.72 & 0.99 & \multirow[t]{2}{*}{0.96} & \multirow[t]{2}{*}{0.337} \\
\hline & Male & 194 & 2.60 & 0.95 & & \\
\hline \multirow[t]{2}{*}{ Entitlement } & Female & 81 & 3.05 & 0.97 & \multirow[t]{2}{*}{-0.14} & \multirow[t]{2}{*}{0.888} \\
\hline & Male & 194 & 3.07 & 0.88 & & \\
\hline \multirow{2}{*}{ Exploitativeness } & Female & 81 & 1.76 & 0.89 & \multirow[t]{2}{*}{-0.048} & \multirow[t]{2}{*}{0.962} \\
\hline & Male & 194 & 1.76 & 0.85 & & \\
\hline
\end{tabular}

$* \mathrm{p}<0.05 * * \mathrm{p}<0.01$

Analysis of variance (ANOVA) test was used to determine the relationship and distribution of narcissistic scale dimensions according to age groups of sports fans. As shown in Table 4, sports fans significantly differed in their responses to the narcissistic scale dimensions of "authority" and "exploitativeness" ( $p<0.01)$. The Tukey and LSD test results were evaluated to determine between which groups this differentiation occurred, and it was found that there was significant difference between all age groups in both dimensions $(\mathrm{p}<0.05)$.

Table 4. ANOVA Result according to Age Groups of Sports Fans

\begin{tabular}{|c|c|c|c|c|c|c|}
\hline Factor & Age & $\mathbf{N}$ & Mean & SD & $\mathbf{F}$ & $\mathbf{P}$ \\
\hline \multirow{3}{*}{ Authority } & $18-25$ & 141 & 3.95 & 0.75 & \multirow{3}{*}{6.05} & \multirow{3}{*}{$0.003 * *$} \\
\hline & $26-35$ & 104 & 4.26 & 0.64 & & \\
\hline & $36<$ & 30 & 4.18 & 0.74 & & \\
\hline \multirow{3}{*}{ Self-sufficiency } & $18-25$ & 141 & 4.20 & 0.72 & \multirow[t]{3}{*}{2.82} & \multirow[t]{3}{*}{0.061} \\
\hline & $26-35$ & 104 & 4.27 & 0.68 & & \\
\hline & $36<$ & 30 & 5.54 & 0.64 & & \\
\hline \multirow{3}{*}{ Superiority } & $18-25$ & 141 & 3.26 & 0.75 & \multirow[t]{3}{*}{1.68} & \multirow[t]{3}{*}{0.187} \\
\hline & $26-35$ & 104 & 3.22 & 0.79 & & \\
\hline & $36<$ & 30 & 3.03 & 0.57 & & \\
\hline \multirow[t]{3}{*}{ Vanity } & $18-25$ & 141 & 3.91 & 0.94 & \multirow[t]{3}{*}{0.22} & \multirow[t]{3}{*}{0.802} \\
\hline & $26-35$ & 104 & 3.86 & 0.88 & & \\
\hline & $36<$ & 30 & 3.80 & 0,79 & & \\
\hline \multirow[t]{3}{*}{ Exhibitionism } & $18-25$ & 141 & 2.67 & 0.97 & \multirow[t]{3}{*}{0.49} & \multirow[t]{3}{*}{0.610} \\
\hline & $26-35$ & 104 & 2.64 & 1.00 & & \\
\hline & $36<$ & 30 & 2.48 & 0.79 & & \\
\hline \multirow[t]{3}{*}{ Entitlement } & $18-25$ & 141 & 3.15 & 0.92 & \multirow[t]{3}{*}{1.90} & \multirow[t]{3}{*}{0.151} \\
\hline & $26-35$ & 104 & 3.01 & 0.84 & & \\
\hline & $36<$ & 30 & 2.82 & 0.98 & & \\
\hline \multirow[t]{3}{*}{ Exploitativeness } & $18-25$ & 141 & 1.92 & 0.98 & \multirow[t]{3}{*}{5.13} & \multirow[t]{3}{*}{$0.006^{* *}$} \\
\hline & $26-35$ & 104 & 1.62 & 0.68 & & \\
\hline & $36<$ & 30 & 1.51 & 0.68 & & \\
\hline
\end{tabular}

$* \mathrm{p}<0.05 * * \mathrm{p}<0.01$ 
Analysis of variance (ANOVA) test was used in order to reveal the relationships and distributions of narcissistic scale dimensions according to the frequencies of sports fans' match watching in the stadium during a season. The results of these analyzes indicate that the narcissism dimensions of "authority" ( $p<0.01)$ and "vanity" ( $p<0.05)$ differ significantly according to the frequency of watching sports in the stadium (Table-6). As a result of the Tukey and LSD tests conducted in order to find out which groups differed in the "authority" dimension, significant differences were found among all groups $(p<0.05)$. According to the results of the Levene test to determine the variance in the "vanity" dimension, the variances were not homogeneously distributed, and according to the results of the Tamhane's T2 test, it was found that there was a significant difference between those who did not watch the matches in the stadium and those who watched four or more matches in the stadium ( $p<0.05)$.

Table 5. ANOVA Result according to the Frequencies of Sports Fans' watching Match in the Stadium during a Season

\begin{tabular}{|c|c|c|c|c|c|c|}
\hline Factor & $\begin{array}{l}\text { Attendance } \\
\text { Frequency }\end{array}$ & $\mathbf{N}$ & Mean & SD & $\mathbf{F}$ & $\mathbf{P}$ \\
\hline \multirow[t]{3}{*}{ Authority } & Never & 116 & 3.93 & 0.79 & \multirow[t]{3}{*}{5.56} & \multirow[t]{3}{*}{$0.004 * *$} \\
\hline & 3 match $<$ & 96 & 4.17 & 0.66 & & \\
\hline & 4 match > & 63 & 4.27 & 0.63 & & \\
\hline \multirow[t]{3}{*}{ Self-sufficiency } & Never & 116 & 4.16 & 0.74 & \multirow[t]{3}{*}{2.05} & \multirow[t]{3}{*}{0.130} \\
\hline & 3 Match < & 96 & 4.34 & 0.63 & & \\
\hline & 4 Match > & 63 & 4.33 & 0.72 & & \\
\hline \multirow[t]{3}{*}{ Superiority } & Never & 116 & 3.22 & 0.74 & \multirow[t]{3}{*}{0.20} & \multirow[t]{3}{*}{0.814} \\
\hline & 3 match $<$ & 96 & 3.26 & 0.79 & & \\
\hline & 4 Match > & 63 & 3.29 & 0.73 & & \\
\hline \multirow[t]{3}{*}{ Vanity } & Never & 116 & 3.73 & 1.02 & \multirow[t]{3}{*}{3.66} & \multirow[t]{3}{*}{$0.027 *$} \\
\hline & 3 Match < & 96 & 3.92 & 0.83 & & \\
\hline & 4 Match > & 63 & 4.10 & 0,70 & & \\
\hline \multirow[t]{3}{*}{ Exhibitionism } & Never & 116 & 2.66 & 0.98 & \multirow[t]{3}{*}{1.47} & \multirow[t]{3}{*}{0.231} \\
\hline & 3 Match < & 96 & 2.52 & 0.98 & & \\
\hline & 4 Match > & 63 & 2.78 & 0.88 & & \\
\hline \multirow[t]{3}{*}{ Entitlement } & Never & 116 & 3.01 & 0.84 & \multirow[t]{3}{*}{0.91} & \multirow[t]{3}{*}{0.401} \\
\hline & 3 Match < & 96 & 3.03 & 0.97 & & \\
\hline & 4 Match > & 63 & 3.20 & 0.92 & & \\
\hline \multirow[t]{3}{*}{ Exploitativeness } & Never & 116 & 1.73 & 0.83 & \multirow[t]{3}{*}{0.292} & \multirow[t]{3}{*}{0.742} \\
\hline & 3 Match < & 96 & 1.74 & 0.91 & & \\
\hline & 4 Match > & 63 & 1.83 & 0.84 & & \\
\hline
\end{tabular}

Analysis of variance (ANOVA) test was used in order to reveal the relationships and distributions of narcissistic scale dimensions according to the frequencies of fans' away match watching over a season. The results demonstrate that the "vanity" dimension varies significantly according to the frequencies of fans' away match in a season. $(p<0.05)$. Tukey and LSD tests were used to determine which groups this variation occurred among. These tests showed that 
the differentiation occurred between those watching no away matches and those watching 4 or more away matches $(\mathrm{p}<0.05)$.

Table 6. ANOVA Result According to the Frequencies of Sports Fans' watching the Match away over a Season

\begin{tabular}{|c|c|c|c|c|c|c|}
\hline Factor & $\begin{array}{l}\text { Attendance } \\
\text { Frequency }\end{array}$ & $\mathbf{N}$ & Mean & SD & $\mathbf{F}$ & $\mathbf{P}$ \\
\hline \multirow[t]{3}{*}{ Authority } & Never & 198 & 4.05 & 0.73 & \multirow[t]{3}{*}{1.22} & \multirow[t]{3}{*}{0.295} \\
\hline & 3 match $<$ & 60 & 4.19 & 0.74 & & \\
\hline & 4 match $>$ & 17 & 4.25 & 0.45 & & \\
\hline \multirow[t]{3}{*}{ Self-sufficiency } & Never & 198 & 4.26 & 0.70 & \multirow[t]{3}{*}{0.26} & \multirow[t]{3}{*}{0.768} \\
\hline & 3 Match < & 60 & 4.25 & 0.71 & & \\
\hline & 4 Match > & 17 & 4.38 & 0.69 & & \\
\hline \multirow[t]{3}{*}{ Superiority } & Never & 198 & 3.21 & 0.73 & \multirow[t]{3}{*}{1.66} & \multirow[t]{3}{*}{0.191} \\
\hline & 3 match $<$ & 60 & 3.31 & 0.82 & & \\
\hline & 4 Match > & 17 & 3.54 & 0.70 & & \\
\hline \multirow[t]{3}{*}{ Vanity } & Never & 198 & 3.80 & 0.91 & \multirow[t]{3}{*}{4.21} & \multirow[t]{3}{*}{$0.016^{*}$} \\
\hline & 3 Match < & 60 & 4.02 & 0.88 & & \\
\hline & 4 Match > & 17 & 4.37 & 0,54 & & \\
\hline \multirow[t]{3}{*}{ Exhibitionism } & Never & 198 & 2.60 & 0.95 & \multirow[t]{3}{*}{0.72} & \multirow[t]{3}{*}{0.486} \\
\hline & 3 Match < & 60 & 2.70 & 0.94 & & \\
\hline & 4 Match > & 17 & 2.86 & 1.17 & & \\
\hline \multirow[t]{3}{*}{ Entitlement } & Never & 198 & 3.08 & 0.90 & \multirow[t]{3}{*}{1.82} & \multirow[t]{3}{*}{0.163} \\
\hline & 3 Match < & 60 & 2.91 & 0.91 & & \\
\hline & 4 Match > & 17 & 3.37 & 0.88 & & \\
\hline \multirow[t]{3}{*}{ Exploitativeness } & Never & 198 & 1.77 & 0.85 & \multirow[t]{3}{*}{0.81} & \multirow[t]{3}{*}{0.898} \\
\hline & 3 Match < & 60 & 1.72 & 0.87 & & \\
\hline & 4 Match > & 17 & 1.75 & 0.99 & & \\
\hline
\end{tabular}

$* \mathrm{p}<0.05 * * \mathrm{p}<0.01$

Analysis of variance (ANOVA) test was used to reveal the relationships and distributions of the narcissistic dimensions according to the teams of the sports fans. The analysis results indicate that the dimension of "authority" varies significantly according to the teams of sports fans $(p<0.05)$. Tukey and LSD tests were used to determine which groups this variation occurred among, and it was observed that the difference was experienced between Galatasaray and Fenerbahce supporters $(\mathrm{p}<0.05)$. 
Vol. 4, No. 3 Özgen et al.: The Turkish Version of the Grandiose Narcissism Scale...

Table 7. ANOVA Result According to the Frequencies of Sports Fans of Teams

\begin{tabular}{|c|c|c|c|c|c|c|}
\hline Factor & Team & $\mathbf{N}$ & Mean & SD & $\mathbf{F}$ & $\mathbf{P}$ \\
\hline \multirow[t]{3}{*}{ Authority } & Galatasaray & 114 & 4.15 & 0.71 & \multirow[t]{3}{*}{4.24} & \multirow[t]{3}{*}{$0.015^{*}$} \\
\hline & Fenerbahce & 86 & 3.91 & 0.83 & & \\
\hline & Besiktas & 75 & 4.21 & 0.55 & & \\
\hline \multirow[t]{3}{*}{ Self-sufficiency } & Galatasaray & 114 & 4.25 & 0.74 & \multirow[t]{3}{*}{0.082} & \multirow[t]{3}{*}{0.922} \\
\hline & Fenerbahce & 86 & 4.26 & 0.74 & & \\
\hline & Besiktas & 75 & 4.29 & 0.60 & & \\
\hline \multirow[t]{3}{*}{ Superiority } & Galatasaray & 114 & 3.28 & 0.78 & \multirow[t]{3}{*}{0.280} & \multirow[t]{3}{*}{0.756} \\
\hline & Fenerbahce & 86 & 3.20 & 0.69 & & \\
\hline & Besiktas & 75 & 3.26 & 0.79 & & \\
\hline \multirow[t]{3}{*}{ Vanity } & Galatasaray & 114 & 3.80 & 0.91 & \multirow[t]{3}{*}{1.095} & \multirow[t]{3}{*}{0.336} \\
\hline & Fenerbahce & 86 & 4.02 & 0.88 & & \\
\hline & Besiktas & 75 & 4.37 & 0,54 & & \\
\hline \multirow[t]{3}{*}{ Exhibitionism } & Galatasaray & 114 & 2.60 & 0.95 & \multirow[t]{3}{*}{0.72} & \multirow[t]{3}{*}{0.486} \\
\hline & Fenerbahce & 86 & 2.62 & 0.94 & & \\
\hline & Besiktas & 75 & 2.71 & 1.17 & & \\
\hline \multirow[t]{3}{*}{ Entitlement } & Galatasaray & 114 & 3.03 & 0.88 & \multirow[t]{3}{*}{0.333} & \multirow[t]{3}{*}{0.717} \\
\hline & Fenerbahce & 86 & 3.13 & 0.92 & & \\
\hline & Besiktas & 75 & 3.03 & 0.93 & & \\
\hline \multirow[t]{3}{*}{ Exploitativeness } & Galatasaray & 114 & 1.81 & 0.92 & \multirow[t]{3}{*}{0.396} & \multirow[t]{3}{*}{0.674} \\
\hline & Fenerbahce & 86 & 1.74 & 0.88 & & \\
\hline & Besiktas & 75 & 1.70 & 0.75 & & \\
\hline
\end{tabular}

$* \mathrm{p}<0.05 * * \mathrm{p}<0.01$

\section{Discussion and Conclusions}

In line with the main objectives of this research, the GNS was adapted to Turkish culture, and the dimensions of the scale were analyzed according to the demographic characteristics and match-watching behaviors of football fans.

Developed by Foster et al. (2015), the GNS was studied for its validity and reliability for the Turkish culture, and a 34-item seven-dimensional structure was obtained by exploratory factor analysis, and this model was confirmed by confirmatory factor analysis. To improve the GNS, Foster et al., (2015) first planned to develop a 35-item question pool whereby 5 questions together measure one dimension. On the basis of a pilot study with a total of 35 items of draft measuring instrument, after the validity study of the phrases "I have a superior personality" that they had planned to be under the dimension of "superiority," and "I expect people to bend the rules for me" that they had planned to be under the dimension of "entitlement" were removed from the ultimate measuring instrument. Our pilot study, however, showed that these expressions were well below the valid dimensions of factor loadings, and were decided to be included in the final instrument of measurement. However, the "born leader" statement under the authority dimension of the 33-item developed by Foster et al., (2015) was excluded from the final measuring instrument because it did not take up enough factor load in our own study. In addition, the 
statements "I expect to get more than average attention" subsumed by the "entitlement" dimension in the GNS, and "I expect attention more than other people do" was put under the "exhibitionism" dimension due to their high factor loads found by our study. An expression in the field of social sciences can have the ability to measure multiple variables together. Therefore, as a result of the studies carried out, it was decided that the ability to measure the "exhibitionism" variable according to our sample group was higher in these two cases, and thus it was decided to be placed under this dimension in the final measurement tool.

NPI developed by Raskin and Terry (1988) was used in a lot of research conducted to determine the narcissistic levels of individuals. The literature confirms that by covering the theoretical aspect of narcissism, NPI measures narcissism highly reliably.

Since the GNS developed by Foster et al., (2015) is very recent, it has not yet been used in any study. However, NPI (Raskin and Terry 1988), which is based on the GNS and is the most widely used measurement tool in the literature, has been used in many different cultures and studies (Foster and Campbell, 2007; del Rosario and White 2005; Tschanz et al., 1998; Horton, Tritch, 2014), including the sports science literature (Brown and Graham, 2008; Miller and Mesagno, 2014).

Emmons (1984) obtained a four-dimensional structure as a result of EFA applied to the data obtained from NPI, and did not reach the sufficient Cronbach's Alpha value in some dimensions. In the study they conducted, del Rosario and White (2005) achieved sufficient level of reliability only for the "authority" dimension on the NPI scale. Except for this dimension, they could not attain sufficient level of reliability in any of the remaining dimensions. Similarly, Foster and Campbell (2007) failed to reach the adequate reliability levels in many dimensions of the NPI. Similar to these studies, Corry et al., (2008) obtained a two-factor structure in their explanatory factor analysis of NPI. Although NPI has been used in many different studies, many of the dimensions of GNS in these studies have not reached adequate levels of reliability. Foster et al., (2015) stated that the solution to this problem lies in creating completely new expressions. Thus, they developed a new measurement tool that is still seven-dimensional but made up entirely of new expressions, and achieved a high level of validity and reliability. As our study suggests, the GNS has sufficient validity and reliability to determine narcissistic levels of sports fans.

GNS dimensions obtained within the scope of the second objective of the study were analyzed for their relationships and distributions as regards to the demographic characteristics of sports fans, their attitudes to participation in matches, and the teams they support. According to this, the responses to the dimension of "authority" in the measurement tool differ significantly according to the gender of the participants. Tschanz et al., (1998) found significant differences between narcissistic levels and gender of individuals in many different dimensions. Similar to this conclusion, Carroll, (1989) found that the narcissistic levels of the participants significantly differed by gender. Similarly, 
Wilson and Sibley (2011) demonstrated that participants' narcissism levels significantly varied by gender. The differences between our research and the results of these studies may be arising due to the use of different measurement tools and statistical analysis methods, or their application to different cultures. In addition, sports fans' personality traits becoming similar over time in a gender-free way may be another reason for such difference in the research results.

Wilson and Sibley (2011) showed that narcissistic levels of individuals are related to their ages and the level of narcissism decreases as age progresses. According to the results of our study, there was a significant difference by their ages between the responses of the individuals to the dimensions of "authority" and "exploitativeness" in the GNS. Foster et al., (2003) found that narcissistic levels of individuals decreased with age. The personality traits of individuals and their characteristics show a significant change with age, especially in transition from adolescence to young adulthood (Ozer and Gjerde, 1989). Therefore, the level of narcissism, which is a personality characteristic, also contributes to the change with age.

No significant differences were found between participants' attitudes towards teams and their participation in matches and the GNS dimensions other than the "authority" dimension. The reason for this may be that the sports fan typologies in the literature are homogeneous in terms of religion, social structure, and culture variables. However, we think that differences regarding the dimensions of narcissism may be greater in countries with more diverse multicultural and multi-faith groups, such as the United States.

\section{Limitation and Future Studies}

As with all research, there are some limitations to the current study, and it suggests avenues for future research consideration. This study focused specifically on a limited number of people and the sample of this study consisted nonrandomly. Therefore result of this study may not be generalizable to Turkey as a whole or to other parts of the country. Future research sampling could consist of randomly for the generalizable results. The participants of this study consist of Besiktas, Galatasaray and Fenerbahce fans. A future study could compares other 14 super league teams' fans. Similarly, future study conducted with fans from different countries in order to better understand whether different sociocultural contexts may influence the narcissism level of the fans.

\section{References}

American Psychiatric Association, (2000). Diagnostic and statistical manual of mental disorders(4th ed., text revision). American Psychiatric Association.

Bagozzi, R. P., and Yi, Y. (1988). On the evaluation of structural equation models. Journal of the academy of marketing science, 16(1), 74-94. 
Bentler, P. M., and Yuan, K. H. (1999). Structural equation modeling with small samples: Test statistics. Multivariate Behavioral Research, 34(2), 181-197.

Bove, L. L., and Johnson, L. W. (2006). Customer loyalty to one service worker: should it be discouraged? International Journal of Research in Marketing, 23(1), 79-91.

Branscombe, N. R., and Wann, D. L. (1991). The positive social and self-concept consequences of sports team identification. Journal of Sport and Social Issues, 15(2), 115-127.

Byrne, B.M. (2001). Structural Equation Modeling With AMOS: Basic Concepts, Applications, and Programming. Lawrence Erlbaum Associates.

Brown, J., and Graham, D. (2008). Body satisfaction in gym-active males: An exploration of sexuality, gender, and narcissism. Sex Roles, 59(1-2), 94-106.

Campbell, W. K., Goodie, A. S., and Foster, J. D. (2004). Narcissism, confidence, and risk attitude. Journal of Behavioral Decision Making, 17(4), 297-311.

Carroll, L. (1989). A comparative study of narcissism, gender, and sex-role orientation among bodybuilders, athletes, and psychology students. Psychological Reports, 64(3), 999-1006.

Child, D. (1990). The essentials of factor analysis. Cassell Educational.

Corry, N., Merritt, R. D., Mrug, S., and Pamp, B. (2008). The factor structure of the Narcissistic Personality Inventory. Journal of Personality Assessment, 90(6), 593-600.

Davis, C. (1992). Body image, dieting behaviors, and personality factors: A study of high-performance female athletes. International Journal of Sport Psychology, 23(3), 179-192.

Davis, C., and Scott-Robertson, L. (2000). A psychological comparison of females with anorexia nervosa and competitive male bodybuilders: body shape ideals in the extreme. Eating behaviors, 1(1), 33-46.

Del Rosario, P. M., and White, R. M. (2005). The Narcissistic Personality Inventory: Test-retest stability and internal consistency. Personality and Individual Differences, 39(6), 1075-1081.

Elman, W. F., and McKelvie, S. J. (2003). Narcissism in football players: Stereotype or reality. Athletic Insight, 5(1), 1-9.

Emmons, R. A. (1984). Factor analysis and construct validity of the narcissistic personality inventory. Journal of Personality Assessment, 48(3), 291-300.

Foster, J. D., McCain, J. L., Hibberts, M. F., Brunell, A. B., and Johnson, R. B. (2015). The Grandiose Narcissism Scale: A Global and Facet-Level Measure of Grandiose Narcissism. Personality and Individual Differences, 73(1), 12-16.

Foster, J. D., Campbell, W. K., and Twenge, J. M. (2003). Individual differences in narcissism: Inflated self-views across the lifespan and around the world. Journal of Research in Personality, 37(6), 469-486.

Foster, J. D., and Campbell, W. K. (2007). Are there such things as "narcissists" in social psychology? A taxometric analysis of the Narcissistic Personality Inventory. Personality and Individual Differences, 43(6), 1321-1332.

Freud, S. (1914). Zur Einführung des Narzißmus-On Narcissism: An Introduction.

Funk, D. C., and James, J. (2001). The psychological continuum model: A conceptual framework for understanding an individual's psychological connection to sport. Sport Management Review, 4(2), 119-150.

Horton, R. S., and Tritch, T. (2014). Clarifying the links between grandiose narcissism and parenting. The Journal of Psychology, 148(2), 133-143.

Gabriel, M. T., Critelli, J. W., and Ee, J. S. (1994). Narcissistic Illusions in SelfEvaluations of Intelligence and Attractiveness. Journal of Personality, 62(1), 143-155. 
Geukes, K., C. Mesagno, S. J., and Kellmann, M. (2012). Testing an interactionist perspective on the relationship between personality traits and performance under public pressure. Psychology of Sport And Exercise, 13(3), 243-250.

Kaiser, H. F. (1974). An index of factorial simplicity. Psychometrika, 39(1), 31-36.

Kernberg, O. F. (1985). Borderline conditions and pathological narcissism. Oxford: Rowman and Littlefield.

Koo, G.-Y., Sung, J., and Martinez, J. M. (2015). Effects of team identification on social and emotional adjustment in higher Education. Journal of Intercollegiate Sport, 8(2), 247 -265.

Linstead, S. (1997). Abjection and Organization: Men, Violence, and Management. Human Relations, 50(9), 1115-1145.

Lothane, Z. (1995). The myth of Narcissism: A methodological analysis. Journal of European Psychoanalysis. 1(2), 31-46

Lubit, R. (2002). The long-term organizational impact of destructively narcissistic managers. Academy of Management Executive, 16(1), 127-138.

Miller, K. J., and Mesagno, C. (2014). Personality traits and exercise dependence: Exploring the role of narcissism and perfectionism. International Journal of Sport and Exercise Psychology, 12(4), 368-381.

Morf, C. C., and Rhodewalt, F. (2001). Unraveling the paradoxes of narcissism: a dynamic self-regulatory processing model. Psychological Inquiry, 12(4), 177-196.

Murrell, A. J., and Dietz, B. (1992). Fan Support of Sport Teams:The Effect of a Common Group Identity. Journal of Sports and Exercise Psychology, 14(1), 28-39.

Ozer, D. J., and Gjerde, P. F. (1989). Patterns of personality consistency and change from childhood through adolescence. Journal of Personality, 57(2), 483-507.

Raskin, R., and Terry, H. (1988). A principal-components analysis of the Narcissistic Personality Inventory and further evidence of its construct validity. Journal of Personality and Social Psychology, 54(5), 890-902.

Robertsa, R., Woodmana, T., Hardya, L., Davisb, L., and Wallacec, H. M. (2013). Psychological skills do not always help performance: the moderating role of narcissism. Journal of Applied Sport Psychology, 25(3), 316-325.

Schwartz, H. S. (1987). Anti-social actions of committed organizational participants: an existential psychoanalytic perspective. Organization Studies, 8(4), 327-340.

Spano, L. (2001). The relationship between exercise and anxiety, obsessive compulsiveness, compulsiveness, and narcissism. Personality and Individual Differences, 49(2), 87-93.

Tschanz, B. T., Morf, C. C., and W.Turner, C. (1998). Gender differences in the structure of narcissism: A multi-sample analysis of the Narcissistic Personality Inventory. Sex Roles, 38(9), 863-870.

Vaknin, S. (2001). Malignant self-love: Narcissism revisited. Narcissus Publishing.

Wallace, H. M., and Baumeister, R. F. (2002). The performance of narcissists rises and falls with perceived opportunity for glory. Journal of Personality and Social Psychology, 82(5), 819-834.

Wilson, M. S., and Sibley, C. G. (2011). Narcissism creep?: Evidence for age-related differences in narcissism in the New Zealand general population. New Zealand Journal of Psychology, 40(3), 89-95.

Zhang, J. J., Pennington-Gray, L., Connaughton, D. P., Braunstein, J. R., Ellis, M. H., Lam, E. T., and Williamson, D. (2003). Understanding women's professional basketball game spectators: sociodemographic, game consumption, and entertainment options. Sport Marketing Quarterly, 12(4). 